\title{
Measuring Symptoms of Moral Injury in Veterans and Active Duty Military with PTSD
}

\author{
Harold G. Koenig, M.D. \\ 1 Departments of Psychiatry and Medicine, Duke University Medical Center, Durham, NC 27710, USA; \\ Harold.Koenig@duke.edu \\ 2 Department of Medicine, King Abdulaziz University, Jeddah, Saudi Arabia
}

Received: 13 December 2017; Accepted: 14 March 2018; Published: 17 March 2018

\begin{abstract}
The Moral Injury Symptom Scale-Military Version (MISS-M) is a 45-item measure of moral injury (MI) symptoms designed to use in Veterans and Active Duty Military with PTSD. This paper reviews the psychometric properties of the MISS-M identified in a previous report, discusses the rationale for the development of the scale, and explores its possible clinical and research applications. The MISS-M consists of 10 theoretically grounded subscales that assess the psychological and spiritual/religious symptoms of MI: guilt, shame, betrayal, moral concerns, loss of meaning/purpose, difficulty forgiving, loss of trust, self-condemnation, spiritual/religious struggles, and loss of religious faith/hope. The scale has high internal reliability, high test-retest reliability, and a factor structure that can be replicated. The MISS-M correlates strongly with PTSD severity, depressive symptoms, and anxiety symptoms, indicating convergent validity, and is relatively weakly correlated with social, spiritual, and physical health constructs, suggesting discriminant validity. The MISS-M is the first multidimensional scale that measures both the psychological and spiritual/religious symptoms of MI and is a reliable and valid measure for assessing symptom severity in clinical practice and in conducting research that examines the efficacy of treatments for MI in Veterans and Active Duty Military personnel.
\end{abstract}

Keywords: moral injury; internal conflict; post-traumatic stress disorder; veterans; active duty military

\section{Introduction}

Veterans and individuals currently serving in the military often have traumatic experiences while participating in combat operations that place them at risk for post-traumatic stress disorder (PTSD). This is evident from research showing that PTSD is one of the most common mental disorders suffered by Veterans seen in the U.S. Veterans Administration Health System (Hoge and Warner 2014; Fulton et al. 2015), and this is also true for Active Duty Military personnel (Lane et al. 2012). PTSD in military settings, especially when it becomes chronic, is notoriously difficult to treat, with only about $20-30 \%$ of persons with this disorder achieving anything close to a full remission of symptoms (Steenkamp et al. 2015; Steinert et al. 2015). PTSD is also often accompanied by extensive psychiatric comorbidity including depression, anxiety, substance abuse, and relationship problems (Ginzburg et al. 2010; Pietrzak et al. 2011). PTSD carries with it a significant risk of suicide in both Active Duty Military (Ramsawh et al. 2014) and Veterans in particular (McKinney et al. 2017; Elbogen et al. 2017).

Moral injury (MI) is a separate syndrome that often accompanies military-related PTSD (Figure 1), and if not addressed, may interfere with treatment response leading to poor outcomes in those with PTSD. The diagnosis of PTSD according to the Diagnostic and Statistical Manual of Mental Disorders, 5th edition (DSM-5) (American Psychiatric Association 2013) is based on four major fear/trauma-based 
symptom clusters that cause functional disability: hyperarousal/irritability, avoidance, emotional negativity/numbing, and intrusive nightmares/flashbacks. PTSD is established as a diagnosis based on (1) extensive research identifying the psychological and physiological changes that characterize this condition and cause functional disability; (2) review by experts of this evidence and agreement by consensus that PTSD warrants an independent separate diagnosis (with specific diagnostic criteria as indicated in the DSM-5 and ICD-10); and (3) research showing that this disorder responds (although often only partially) to a range of psychological and pharmacological treatments designed specifically to target it.

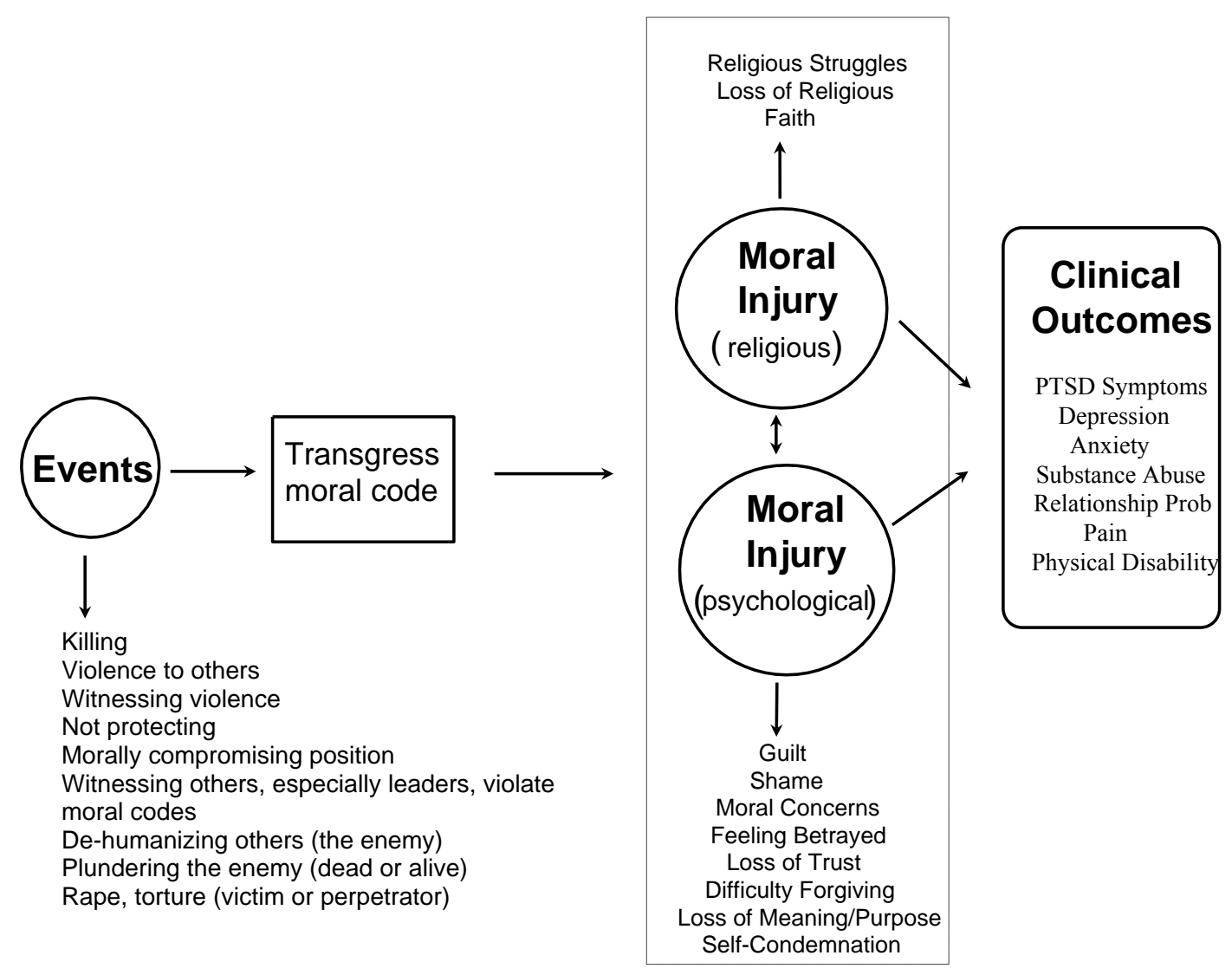

Figure 1. Illustration of the relationship between traumatic events, moral injury, PTSD and comorbid psychological, social, behavioral, and physical outcomes (adapted from Koenig et al. (2017), used with permission).

In contrast, the symptoms of MI according to trauma experts, result from "perpetrating, failing to prevent, bearing witness to, or learning about acts that transgress deeply held moral beliefs" (Litz et al. 2009, p. 695); "a betrayal of what's right, by someone who holds legitimate authority, in a high-stakes situation" (Shay 1994; Shay 2014, p. 183); or "a deep sense of transgression including feelings of shame, grief, meaninglessness, and remorse from having violated core moral beliefs" (Brock and Lettini 2012, p. xiv). Thus, MI involves a compilation of symptoms that often accompanies PTSD, but has not yet been subject to the kind of research and consensus among experts in the field that is necessary to call it a separate disorder or diagnosis deserving inclusion in the DSM or ICD diagnostic nomenclature. MI, then, is a "syndrome" in need of further study in order to distinguish it from PTSD and other psychiatric conditions, to examine its effects on psychological, social, and occupational functioning, and to determine treatment response. In this respect, then, MI is not yet an established and billable diagnosis like PTSD. 
The moral dilemmas, ethical questions, and guilt caused by actions and experiences during wartime have been the subject of academic discussion since the early 1980's (Friedman 1981), although researchers did not begin to define and truly study this construct until nearly 30 years later when MI was highlighted in a seminal article published by Brett Litz and colleagues (Litz et al. 2009).

\section{Measurement}

During the ensuing years, two measures of MI were developed and psychometrically validated. The first one, a 9-item scale, was developed by military psychiatrist William P. Nash and colleagues (Nash et al. 2013) in active duty U.S. marines and was called the Moral Injury Events Scale (MIES). The second measure of MI, a 19-item scale, was developed by psychologist Joseph M. Currier and colleagues (Currier et al. 2015b) and called the Moral Injury Questionnaire-Military Version (MIQ-M). Both of these scales measured the actual occurrence of traumatic experiences (e.g., "I acted in ways that violated my own moral code or values" or "I was involved in the death of an innocent in the war") and the severity of current symptoms caused by those events (i.e., "I am troubled by having acted in ways that violated my own morals or values"). Because of this combination of events and symptoms, such measures while useful for diagnostic purposes, are less helpful for following changes in response to treatment. Effective interventions are likely to change the symptoms of MI, but will not change the fact that the traumatic event occurred. Furthermore, neither of the scales above assess religious or spiritual struggles or changes in religious faith, factors known to adversely affect those with PTSD. As a result, we developed a new multi-dimensional measure of MI symptoms, the Moral Injury Symptom Scale-Military Version (MISS-M) that takes both of these concerns into account (Koenig et al. 2018a).

\section{Objectives}

The purpose of this paper is to (1) discuss the development of the MISS-M, (2) review the psychometric properties of the scale reported previously (Koenig et al. 2018a), (3) explore the clinical and research applications of this scale, and (4) provide a copy of the instrument in the Appendix A of this article.

\section{Development of the Moral Injury Symptom Scale-Military Version (MISS-M)}

In reviewing the literature on MI, our interdisciplinary team of mental health and religious professionals came up with 10 theoretically-grounded dimensions that characterize this syndrome based on the writings and research of trauma experts (Litz et al. 2009; Shay 1994; Shay 2014; Brock and Lettini 2012; Nash et al. 2013; Currier et al. 2015b; Drescher et al. 2011). We identified eight psychological dimensions of MI (guilt, shame, betrayal by others, moral concerns, loss of meaning/ purpose, difficulty forgiving, loss of trust, and self-condemnation) and two spiritual/religious dimensions (spiritual/religious struggles and loss of religious faith/hope). We then populated these dimensions with 54 items that were derived from existing scales and from additional items developed by our team based on the strong face validity of item content. The rationale for including each of the 10 dimensions and the items included in them are reviewed below.

\subsection{Guilt}

Veterans are frequently plagued by feelings of guilt over actions perpetrated during combat or over failing to protect one's comrades or innocent civilians. It doesn't matter whether such actions result from simply doing one's duty as a soldier, being ordered to do so by those in command, or losing control and doing things out of rage or vengeance. These actions inevitably leave moral scars-and one of those scars is guilt. Feelings of guilt have long been associated with PTSD resulting from combat experiences (Hendin and Haas 1991; Lee et al. 2001), have been specifically labeled as a form of MI (Litz et al. 2009), and have been assessed in both existing MI measures (Nash et al. 2013; Currier et al. 2015b) prior to the development of the MISS-M. This dimension, then, was considered essential for inclusion in the MISS-M. Five questions were initially used to assess guilt, two from 
the MIQ-M (Currier et al. 2015b) and three items from the Combat Guilt Scale (CGS)-a 15-item multi-dimensional measure of guilt developed in combat Veterans (Henning and Frueh 1997). These questions focus on feeling guilty over failing to save a life, surviving when others didn't, and feeling bad over enjoying the hurting or killing others.

\subsection{Shame}

While often used interchangeably, shame and guilt are two quite different constructs. In the psychoanalytic literature, shame and guilt are both functions of the superego (Lewis 1971). Shame involves greater self-consciousness and self-imaging; i.e., it is more about personal identity. Shame is a feeling about the self that arises from the consciousness of having done something dishonorable or improper (it is about ourselves), whereas guilt is the remorse that one feels for having committed a crime or wrongful act affecting others (it is about others). Depending on the particular personality of the individual, one may experience either shame or guilt or both as a result of actions during wartime-for example, shame over having deserted one's comrades during the heat of battle to save oneself, or guilt over having killed innocents during a fit of rage. Shame is a form of injury to a person's self-identity. As with guilt, shame is extensively referred to in both the psychological and theological literature on MI (Litz et al. 2009; Drescher et al. 2011; Worthington and Langberg 2012). Therefore, two questions were used to assess shame in the MISS-M, one from the CGS and one from the work of Andrews and colleagues (Andrews et al. 2009) studying shame in Veterans. Both focus on measuring feelings of shame towards oneself for what was done or not done during combat operations.

\subsection{Betrayal}

In the classic text by military psychiatrist Jonathan Shay, Achilles in Vietnam, he emphasized the central role that feelings of betrayal play in the construct of MI (Shay 1994). Achilles is betrayed by his commander, Agamemnon, leading to rage towards his commander and feelings of care for only a small group of companion fighters. As noted earlier, Shay defined moral injury as "a betrayal of what's right, by someone who holds legitimate authority, in a high-stakes situation" (Shay 2014). These feelings of betrayal during wartime usually involve betrayal by others in authority (e.g., those who gave the order to kill), but also may involve a betrayal by oneself or one's moral standards, or after returning back to civilian life, betrayal by a community that one fought for (as was often experienced by Vietnam Veterans returning home). The dimension of betrayal in the MISS-M was assessed by the 3-item betrayal subscale of Nash and colleagues' MIES (Nash et al. 2013) that focuses on feeling betrayed by leaders, fellow service members, and those outside the military.

\subsection{Violation of Moral Values}

At the heart of MI is the violation of moral values. Such violation involves perceived transgressions of deeply held moral or ethical beliefs that are perpetrated by either oneself or others. Besides assessing betrayal (as noted above), the MIES also measures the violation of moral values. This dimension of MI was measured by Nash and colleagues using six questions, three assessing commission and three assessing omission. These questions were arrived at by a literature review, the generation of a pool of items by trauma experts, a selection of items by consensus, and ultimately a factor analysis to identify those items that best measured this dimension (Nash et al. 2013). These questions focused on witnessing, perpetrating, and distress related to such transgressions; three of the six involve events and three involve feelings. Therefore, given its focus on symptoms, the MISS-M included the three questions from the MIES that assess feelings in order to measure concerns related to (1) witnessing others' immoral acts, (2) perpetrating immoral acts themselves, and (3) failing to act when feeling morally obliged to do so. 


\subsection{Loss of Meaning}

Loss of meaning and related existential concerns were one of the key aspects of MI identified by Drescher and colleagues during interviews with 23 seasoned mental health and religious professionals who had years of experience providing care to Active Duty Military personnel and Veterans (Drescher et al. 2011, p. 11). Loss of meaning was also the central focus of a report by Fontana and Rosenheck (Fontana and Rosenheck 2005) in a study of 1,168 Vietnam era Veterans struggling with PTSD symptoms. These investigators found that Veterans who had difficulty coping with combat trauma often experienced a loss of meaning in their lives, and frequently sought help from mental health professionals and clergy (in particular) when dealing with such issues. This prompted investigators to recommend that greater consideration be given to addressing existential issues in the treatment of PTSD. This dimension of MI, then, seemed essential to include. Consequently, loss of meaning was assessed in the MISS-M by six questions, five taken from a subscale of the 10-item Meaning in Life Questionnaire (Steger et al. 2006) that measures the extent to which a person feels his/her life has meaning. In addition, one item was taken from the MIQ-M (Currier et al. 2015b) that asks how exposure to death during war has changed the person.

\subsection{Difficulty Forgiving}

Nearly 15 years ago, Witvliet and colleagues (Witvliet et al. 2004) reported that difficulty forgiving was strongly linked to PTSD symptoms in Vietnam Veterans. Litz and colleagues (Litz et al. 2009) emphasized the difficulty that many military personnel have in forgiving themselves for what some believe are unforgiveable things they did during the heat of battle. Litz and colleagues go on to emphasize that both self-forgiveness and forgiveness of others are key to overcoming the moral injuries that involve guilt, shame, and self-condemnation for actions perpetrated during war, and letting go of anger towards those in authority whom they believe betrayed them. Likewise, Worthington and Langberg (Worthington and Langberg 2012) stressed the devastating effects of harboring resentments and unforgiveness towards self and others, describing secular and religiously tailored programs to help such individuals forgive themselves and others. The need to forgive God has also been described in studies of morally injured Veterans (Currier et al. 2014; Johnson 2014).

For the MISS-M, ten questions were initially chosen to assess difficulties forgiving others, self, and God as a result of wartime experiences. Six of these items came from the Heartland Forgiveness Scale (HFS) (Thompson et al. 2005). The HFS has been used in Veteran populations and the overall score is inversely correlated with PTSD symptoms, a relationship that is mediated by anger and negative affect (Karairmak and Guloglu 2014). In addition, four questions were developed by our research team to assess feeling forgiven by God, forgiving God, forgiving self, and the need to seek forgiveness in the first place.

\subsection{Loss of Trust}

Drescher and colleagues emphasized that the loss of trust resulting from feelings of betrayal often haunts those with MI and interferes with their ability to maintain family relationships and friendship networks (Drescher et al. 2011). Likewise, in a qualitative study of Vietnam and non-Vietnam Veterans, Flipse Vargas and colleagues (Flipse Vargas et al. 2013) found that loss of trust in the government and people in general was a recurrent theme identified as a problem these Veterans struggled with as a result of wartime experiences. Similarly, Kopacz and colleagues (Kopacz et al. 2016) emphasized the lack of trust that many morally injured veterans experienced as a result of what was done to them during wartime, and may use as an excuse to continue hurting others after returning home. Thus, in order to capture this dimension, six questions were taken from the General Trust Scale (Yamagishi and Yamagishi 1994) to assess the extent to which the person believes that other people are honest and trustworthy, basically good and kind, respond similarly if trusted, and also, to what extent the person feels he or she can be trusted by others. 


\subsection{Self-Condemnation}

Self-condemnation and low sense of self-esteem have been repeatedly emphasized by trauma experts as a key dimension of MI (Litz et al. 2009; Worthington and Langberg 2012; Maguen and Litz 2012; Litz et al. 2017). Unresolved guilt, shame, and difficulty forgiving oneself drive this negative moral emotion that often leads to depression and in some cases even suicide (Worthington and Langberg 2012; Kopacz et al. 2016; Bryan et al. 2016). In order to capture this dimension, ten items from the Rosenberg Self-Esteem Scale (SES) (Rosenberg 1965) were used to assess self-condemnation and self-deprecation. The SES is a standard measure of global self-worth that measures both positive and negative feelings about the self.

\subsection{Spiritual/Religious Struggles}

There is growing evidence that spiritual/religious struggles are strongly correlated with PTSD symptoms in military populations (particularly Veterans) and appear to impede recovery and adversely affect physical health. Spiritual struggles related to trauma during wartime include feeling punished by God for actions done (violence/killing) or not done (protection of innocents); questioning God's power and control for not having protected oneself or one's comrades from assault, injury, or death; feeling deserted by one's faith community after returning home from military service; and internal struggles over whether God is loving, caring or concerned about people, if allowing horrific events to take place. The presence of religious struggles of this type were found to predict a slower recovery from PTSD among 532 Veterans admitted to a 60-90 day residential PTSD treatment program (Currier et al. 2015a). Based on these findings and other research documenting strong positive associations between religious struggles and PTSD symptoms (Currier et al. 2015b; Witvliet et al. 2004; Currier et al. 2014), seven items from the negative religious coping subscale of the Brief RCOPE (Pargament et al. 1998) were used in the MISS-M to assess spiritual/religious struggles. This 7-item subscale has been shown to predict greater mortality in Veterans (Pargament et al. 2001) and has been associated with higher pro-inflammatory cytokine levels (interleukin-6) in medically ill populations (Ai et al. 2009).

\subsection{Loss of Religious Faith/Hope}

Research shows that loss of religious faith is present in $30 \%$ of Veterans and is associated with prolonged use of VA mental health services among those with PTSD (Fontana and Rosenheck 2004). In that study of 1385 Veterans being treated for PTSD symptoms (95\% serving in Vietnam), participants were asked "How much was/is religion a source of strength and comfort to you?" This question was asked for two periods-at the time they entered the military and currently. The difference in religious comfort between the two periods was calculated, with $29 \%$ reporting that religion had become less of a source of comfort. Loss of religious faith in that study was found to be a stronger predictor of number of outpatient mental health treatment sessions than was social support (number of persons they felt close to), previous experiences of violence encountered, or ability to hold down a full-time job. There is also an extensive literature showing a strong association between religious faith and the spiritual concept of hope, suggesting a close link between these two separate but related constructs (Clarke 2003; Koenig et al. 2012, p. 302). Thus, a dimension of MI that assessed loss of religious faith and hope seemed appropriate, and its inclusion in the MISS-M is supported by work of theologians and mental health professionals in the trauma literature (Litz et al. 2009; Drescher et al. 2011; Worthington and Langberg 2012). Two items make up this subscale of the MISS-M, one that was adapted from the study of Vietnam Veterans above that asks about loss of religious faith as a result of wartime experiences (Fontana and Rosenheck 2004). The second question, developed by study authors based on its strong face validity, asks about loss of hope in the future.

Thus, the MISS-M is composed of 10 subscales that comprehensively assess the construct of MI, are theoretically grounded on how trauma experts define MI, and are made up of items from both 
established scales and from items crafted by our study team to best capture the psychological and spiritual/religious conflicts that are the core of MI.

\section{Psychometric Properties of the MISS-M}

The 54 items above were administered to 427 Veterans and Active Duty Military with PTSD symptoms resulting from serving in a combat zone (Koenig et al. 2018a). Participants were recruited from the Veterans Administration Medical Center (VAMC) in Durham, North Carolina; the Charlie Norwood VAMC in Augusta, Georgia; the Veterans Administration Greater Los Angeles Healthcare System; the Michael E. DeBakey VAMC in Houston, Texas; the South Texas Veterans Health Care System; and Liberty University in Lynchburg, Virginia. Over $86 \%$ of participants scored 33 or higher on the PTSD Checklist-DSM-5 Military Version (PCL-5) (Weathers et al. 2013) indicating relatively severe PTSD symptoms (unpublished data). All questionnaires were filled out in-person except at the Liberty University site (Active Duty Military only) where the questionnaire was completed online. Each of the 54 items on the MISS-M was rated on a scale from 1 to 10 in terms of agreement or disagreement, reverse scoring items as necessary so that higher scores indicate greater MI.

\subsection{Factor Analysis}

The overall sample was randomly split into two groups. In the first group $(n=214)$, exploratory factor analysis (EFA) was performed on the original 54 items. In the second group $(n=213)$, those items that met the cutoff criterion (factor loadings $\geq 0.45$ on EFA) were subject to confirmatory factor analysis (CFA). As noted above, each one of the 10 dimensions of MI chosen has a strong theoretical rationale that justifies its inclusion in the MISS-M. Therefore, to ensure that items with strong face validity for a particular dimension ended up on the subscale assessing that dimension, EFA and CFA were conducted at the subscale level.

EFA revealed a single factor for each dimension/subscale of the MISS-M except for the difficulty forgiving and self-condemnation subscales, for which two factors were identified (based entirely on whether a question was stated in a positive or a negative direction). Of the 54 items assessed, 9 failed to meet the factor loading cut-off criterion, resulting in the final 45 -item MISS-M. These 45 items were then subjected to CFA again at the subscale level in the second sample. The resulting factor loadings were $0.41-0.76$ for the 4-item guilt subscale, 0.78 for the 2-item shame subscale, $0.56-0.91$ for the 3-item betrayal subscale, $0.66-0.89$ for the 3-item moral concerns subscale, $0.73-0.90$ for the 4 -item loss of meaning subscale, $0.42-0.78$ for factor 1 and $0.60-0.77$ for factor 2 of the 7-item difficulty forgiving subscale, $0.73-0.93$ for the 4 -item loss of trust subscale, $0.65-0.81$ for factor 1 and $0.74-0.84$ for factor 2 of the 10-item self-condemnation subscale, $0.52-0.87$ for the 6-item spiritual/religious struggles subscale, and 0.58 for the 2 -item loss of religious faith/hope subscale. With the exception of the loss of religious faith/hope subscale, eigenvalues for all factors making up the subscales were equal to or exceeded 1.0 (range 1.55 to 10.94) (based on the Kaiser-Guttman rule) (Kaiser 1991). Thus, overall, CFA replicated the factor structure of subscales making up the 45-item MISS-M.

\subsection{Reliability}

In the overall sample $(n=427)$, the internal consistency (Cronbach's alpha) of the 45-item MISS-M was acceptable $(\alpha=0.92,95 \% \mathrm{CI}=0.91-0.93)$, as was the reliability of most of the individual subscales ( $\alpha$ range $0.56-0.91$ ). Internal consistency $\alpha^{\prime}$ s of 0.70 or higher are considered adequate (Cronbach 1951). The test-retest reliability of the overall 45-item MISS-M was assessed in 64 Veterans after an average of 10 days. The intra-class correlation coefficient (ICC) demonstrated high test-retest reliability for the overall MISS-M (ICC $=0.91,95 \% \mathrm{CI}=0.85-0.95$ ) and ICC's of 0.78 to 0.90 for individual subscales. ICC's of 0.70 or higher are considered adequate (Shrout and Fleiss 1979). 


\subsection{Validity}

In addition to the factor analytic validity demonstrated by the CFA above, construct validity of the 45-item MISS-M was indicated by high correlations between the 10 subscales and the total MISS-M score (Pearson r's ranging from 0.45 to 0.78 ). Discriminant validity was suggested by relatively weak correlations between the total MISS-M score and other social, religious and physical health constructs such as involvement in community activities $(r=-0.33)$, importance of religion $(r=-0.23)$ or spirituality $(-0.18)$, severity of physical pain $(r=0.21)$, and impairment of physical functioning $(r=0.27)$. Finally, convergent validity was indirectly demonstrated by relatively strong correlations with other psychiatric symptoms that one might hypothesize would accompany MI, such as PTSD symptoms (assessed by the 20-item PCL-5) $(r=0.56)$, depressive symptoms (assessed by the 14-item Hospital Anxiety and Depression Scale; HADS (Zigmond and Snaith 1983) ( $\mathrm{r}=0.62$ ), and anxiety symptoms (also assessed by the HADS) $(\mathrm{r}=0.59)$. Convergent validity could not be tested directly because the MISS-M is the first multi-dimensional measure of MI symptom severity (severity of symptoms alone, not including MI events) (published online on December 1, 2017), and there were no other pure MI symptom severity measures to compare it with at the time the study was conducted (September 17, 2015, through August 1, 2017).

\section{Prevalence of Moral Injury Symptoms}

Scores on individual items of the MISS-M provided an indication of the prevalence of significant MI symptoms in this sample of Veterans and Active Duty Military. The average score on the 45-item MISS-M was 223.6 (SD = 61.6, with a range of 86 to 403). Nearly $90 \%$ of participants indicated a 9 or 10 on a 1 to 10 severity scale for at least one MI symptom and half $(50 \%)$ gave this rating for more than five of the $45 \mathrm{MI}$ symptoms. Dimensions with the highest scores (indicating greater MI) were the loss of trust and moral concerns subscales, with items on these subscales averaging 5.8 on the 1 to 10 response range.

Thus, MI as assessed by the MISS-M was widespread and strongly correlated with severity of PTSD and comorbid depression and anxiety among these Veterans and Active Duty Military, most of whom had relatively severe PTSD symptoms from serving in combat.

\section{Limitations}

The MISS-M was designed specifically to cover the dimensions of MI that experts in the field have indicated are part of the MI construct. As such, we conducted the factor analysis at the subscale level to ensure that each of these dimensions were included in the final scale. Not all psychometricians may agree with this approach, but our team felt that being comprehensive in our assessment of this construct took first priority. Another concern about the MISS-M is that the loss of religious faith/hope dimension had a relatively low alpha (0.56), which is below the threshold of 0.70 . Nevertheless, given the strong face validity of these items, we felt that this subscale should be included-particularly given the evidence that this dimension might interfere with treatment response in PTSD (Fontana and Rosenheck 2004). Finally, given the small number of Active Duty Military personnel in our validation study $(n=54)$, further research is needed to replicate the psychometric properties of the MISS-M in this population, as well as in other populations of Veterans from different regions of the U.S. and from other countries.

\section{Clinical and Research Applications of the MISS-M}

As a symptom measure of MI severity, the MISS-M has at least two potential applications: (1) in clinical settings to screen for MI symptoms and (2) in research settings to examine relationships between MI, mental health, and physical health outcomes, and to assess change over time in response to interventions that target MI symptoms. 


\subsection{Clinical Applications}

The MISS-M may be used to screen Veterans and Active Duty Military with PTSD symptoms in order to identify those who are also suffering from MI (which may be preventing the successful treatment of PTSD). While no cutoff on the MISS-M has yet been determined that indicates significant MI that requires intervention (see below), scores on the individual subscales may give some indication of where problems exist that require clinical attention from mental health professionals and/or trained clergy (chaplains or pastoral counselors). Interventions have been developed (or are being developed) to treat the psychological symptoms of MI (Litz et al. 2017; Steenkamp et al. 2011; Maguen and Burkman 2013; Paul et al. 2014) and to treat both the psychological and the spiritual/religious symptoms (Harris et al. 2011; Koenig et al. 2017; Pearce et al. 2018). Many of these interventions, with some exceptions (Litz et al. 2017; Koenig et al. 2017; Pearce et al. 2018), were not designed specifically to target MI but rather to treat specific MI symptoms like guilt or shame, or PTSD symptoms more generally (given that until the MISS-M was developed there was no multi-dimensional measure that only assessed MI symptom severity). Nevertheless, be aware that there are interventions out there that may help to relieve MI whether that occurs in Veterans, Active Duty Military personnel, or even those not in the military who are disabled with PTSD (from rape or others forms of trauma).

\subsection{Research Applications}

Researchers may find the MISS-M useful for both observational and experimental studies in current or former military personnel. The MISS-M may be used in studies that examine the relationship between MI symptoms and mental health outcomes such as PTSD, depression, anxiety, substance use, relationship problems, occupational difficulties, chronic pain, and impairments in physical functioning. These may be either cross-sectional studies that establish an association or longitudinal studies that examine the effects of MI on these outcomes over time. The MISS-M may also be used in randomized clinical trials that seek to examine the effects of interventions on relieving the symptoms of MI. As suggested above, research examining the effects of interventions on MI has been lacking because a pure MI symptom measure that could be assessed over time in clinical trials until now has not been available. The existence of the MISS-M helps to fill that gap and may now be used to assess the effects of treatments directed specifically at reducing MI symptoms. To assist in this regard, future research is needed to identify a cutoff point on the MISS-M that indicates clinically significant symptoms with functional impairment (or is sufficient to block successful treatment of PTSD) that require intervention. In addition, research is needed to determine if scores on the MISS-M are sensitive to change over time (and to identify a clinically significant change score). Such studies are forthcoming, along with the development of a 10-item short form of the MISS-M (the MISS-M-SF), which as with the long version described in this article, may be used as either a screening tool for clinical applications or as an outcome measure or predictor of health outcomes in research studies (Koenig et al. 2018b).

\section{Conclusions}

Moral injury is widespread among Veterans and Active Duty Military personnel with PTSD symptoms resulting from experiences in combat. Unless addressed, MI may interfere with the successful treatment (both psychological and pharmacological) of PTSD. Until now, there was no pure MI symptom scale that could be used as an outcome measure to test the efficacy of various interventions directed specifically at reducing MI. The Moral Injury Symptom Scale-Military Version is a reliable and valid measure for assessing symptoms of MI. The MISS-M may be used to screen Veterans and Active Duty Military for MI, and may be utilized in clinical trials to determine the efficacy of treatments for this common and widespread syndrome that often accompanies PTSD.

Conflicts of Interest: The author declares no conflict of interest. 


\section{Appendix A}

\section{The Moral Injury Symptom Scale-Military Version (long-form)}

Introduction: The following statements/questions may be difficult, but they are common experiences of combat Veterans or Active Duty Military returning from battle. They concern your experiences while in a combat or war zone and how you are feeling now. Just do the best you can, and try to answer every question. Circle a single number between 1 and 10 for each ("strongly disagree" to "strongly agree"):

\section{$\underline{\text { Guilt }}$}

1. I feel guilt for surviving when others didn't.

2. I feel guilt over failing to save the life of someone in war.

3. Some of the things I did during the war out of anger or frustration continue to bother me.

4. It bothers me sometimes that I enjoyed hurting/killing people during the war.

\section{Shame}

5. If people knew more about the things I did during the war they would think less of me.

6. I feel ashamed about what I did or did not do during this time.

Betrayal

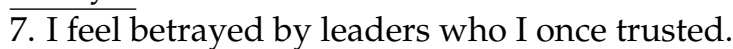

8. I feel betrayed by fellow service members who I once trusted.

9. I feel betrayed by others outside the US military who I once trusted.

Violation of Moral Values

10. I am troubled by having witnessed others' immoral acts.

11. I am troubled by having acted in ways that violated my own morals or values.

12. I am troubled because I violated my morals by failing to do something that I felt I should've done.

Loss of Meaning

Introduction: Circle a single number between 1 and 10 that describes how true each statement is for you ("absolutely untrue" to "absolutely true"):

13. I understand my life's meaning.

14. My life has a clear sense of purpose.

15. I have a good sense of what makes my life meaningful.

16. I have discovered a satisfying life purpose.

Difficulty Forgiving

Introduction: Circle a single number between 1 and 10 that describes how true or false each statement is for you ("almost always false of me" to "almost always true of me"):

17. Although I feel bad at first when I mess up, over time I can give myself some slack.

18. I hold grudges against myself for negative things I've done.

19. It is really hard for me to accept myself once I've messed up.

20. I don't stop criticizing myself for negative things I've felt, thought, said, or done.

21. I believe that God has forgiven me for what I did during combat.

22. I have forgiven God for what happened to me or others during combat.

23. I have forgiven myself for what happened to me or others during combat.

Loss of Trust

Introduction: Circle a single number between 1 and 10 that describes how much you agree or disagree with each statement ("strongly disagree" to "strongly agree"):

24. Most people are basically honest.

25. Most people are trustworthy.

26. Most people are basically good and kind. 
27. Most people are trustful of others.

\section{Self-Condemnation}

Introduction: Circle a single number between 1 and 10 for each statement ("strongly disagree" to "strongly agree"):

28. On the whole, I am satisfied with myself.

29. At times I think I am no good at all.

30. I feel that I have a number of good qualities.

31. I am able to do things as well as most other people.

32. I feel I do not have much to be proud of.

33. I certainly feel useless at times.

34. I feel that I'm a person of worth, at least on an equal plane with others.

35. I wish I could have more respect for myself.

36. All in all, I am inclined to feel that I am a failure.

37. I take a positive attitude toward myself.

Introduction: Below are feelings that combat Veterans often have due to combat experiences. How much have you? Circle a single number between 1 and 10 for each statement ("a great deal" or "very true" to "not at all" or "very untrue"):

Spiritual/Religious Struggles

38. I wonder whether God had abandoned me.

39. I felt punished by God for my lack of devotion.

40. I wondered what I did for God to punish me.

41. I questioned God's love for me.

42. I questioned the power of God.

43. I wondered whether my church had abandoned me.

Loss of Religious Faith/Hope

44. Compared to when you first went into the military has your religious faith since then ... ("weakened a lot," "weakened a little," "strengthened a little," "strengthened a lot")

45. How hopeful are you about the future? ("not at all" to "very hopeful")

Scoring: First, reverse score items 13-16, 17, 21-28, 30-31, 34, 37, and 44-45, and then sum all items together (or those of individual subscales if subscale scores are desired). Possible score range is 45 to 450 , with higher scores indicating more severe moral injury. For a fully formatted version of the 45-item MISS-M (and the 10-item MISS-M-SF), contact the author: Harold.Koenig@duke.edu.

\section{References}

Ai, Amy L., E. Mitchell Seymour, Terrence N. Tice, Ziad Kronfol, and Steven F. Bolling. 2009. Spiritual struggle related to plasma interleukin-6 prior to cardiac surgery. Psychology of Religion and Spirituality 1: 112-28. [CrossRef]

American Psychiatric Association. 2013. Diagnostic and Statistical Manual of Mental Disorders (DSM- $\left.5^{\circledR}\right)$. Arlington: American Psychiatric Association Publishing.

Andrews, Bernice, Chris R. Brewin, Lorna Stewart, Rosanna Philpott, and Jennie Hejdenberg. 2009. Comparison of immediate-onset and delayed-onset posttraumatic stress disorder in military veterans. Journal of Abnormal Psychology 118: 767-77. [CrossRef] [PubMed]

Brock, Rita Nakashima, and Gabriella Lettini. 2012. Soul Repair: Recovering from Moral Injury after War. Boston: Beacon Press.

Bryan, Craig J., AnnaBelle O. Bryan, Michael D. Anestis, Joye C. Anestis, Bradley A. Green, Neysa Etienne, Chad E. Morrow, and Bobbie Ray-Sannerud. 2016. Measuring moral injury: Psychometric properties of the Moral Injury Events Scale in two military samples. Assessment 23: 557-70. [CrossRef] [PubMed]

Clarke, David. 2003. Faith and hope. Australasian Psychiatry 11: 164-68. [CrossRef] 
Cronbach, Lee J. 1951. Coefficient alpha and the internal structure of tests. Psychometrika 16: 297-334. [CrossRef]

Currier, Joseph M., Kent D. Drescher, and J. Irene Harris. 2014. Spiritual functioning among veterans seeking residential treatment for PTSD: A matched control group study. Spirituality in Clinical Practice 1: 3-15. [CrossRef]

Currier, Joseph M., Jason M. Holland, and Kent D. Drescher. 2015a. Spirituality factors in the prediction of outcomes of PTSD treatment for U.S. military veterans. Journal of Traumatic Stress 28: 57-64. [CrossRef] [PubMed]

Currier, Joseph M., Jason M. Holland, Kent Drescher, and David Foy. 2015b. Initial psychometric evaluation of the moral injury questionnaire-Military Version. Clinical Psychology E Psychotherapy 22: 54-63.

Drescher, Kent D., David W. Foy, Caroline Kelly, Anna Leshner, Kerrie Schutz, and Brett Litz. 2011. An exploration of the viability and usefulness of the construct of moral injury in war veterans. Traumatology 17: 8-13. [CrossRef]

Elbogen, Eric B., H. Ryan Wagner, Nathan A. Kimbrel, Mira Brancu, Jennifer Naylor, Robert Graziano, and Eric Crawford. 2017. Risk factors for concurrent suicidal ideation and violent impulses in military veterans. Psychological Assessment. [CrossRef] [PubMed]

Flipse Vargas, Alison, Thomas Hanson, Douglas Kraus, Kent Drescher, and David Foy. 2013. Moral injury themes in combat veterans' narrative responses from the National Vietnam Veterans' Readjustment Study. Traumatology 19: 243-50. [CrossRef]

Fontana, Alan, and Robert Rosenheck. 2004. Trauma, change in strength of religious faith, and mental health service use among veterans treated for PTSD. Journal of Nervous and Mental Disease 192: 579-84. [CrossRef] [PubMed]

Fontana, Alan, and Robert Rosenheck. 2005. The role of loss of meaning in the pursuit of treatment for posttraumatic stress disorder. Journal of Traumatic Stress 18: 133-36. [CrossRef] [PubMed]

Friedman, Matthew J. 1981. Post-Vietnam syndrome: Recognition and management. Psychosomatics 22: 931-43. [CrossRef]

Fulton, Jessica J., Patrick S. Calhoun, H. Ryan Wagner, Amie R. Schry, Lauren P. Hair, Nicole Feeling, Eric Elbogen, and Jean C. Beckham. 2015. The prevalence of posttraumatic stress disorder in Operation Enduring Freedom/Operation Iraqi Freedom (OEF/OIF) Veterans: A meta-analysis. Journal of Anxiety Disorders 31: 98-107. [CrossRef] [PubMed]

Ginzburg, Karni, Tsachi Ein-Dor, and Zahava Solomon. 2010. Comorbidity of posttraumatic stress disorder, anxiety and depression: A 20-year longitudinal study of war veterans. Journal of Affective Disorders 123: 249-57. [CrossRef] [PubMed]

Harris, J. Irene, Christopher R. Erbes, Brian E. Engdahl, Paul Thuras, Nichole Murray-Swank, Dixie Grace, and Henry Ogden. 2011. The effectiveness of a trauma focused spiritually integrated intervention for veterans exposed to trauma. Journal of Clinical Psychology 67: 425-38. [CrossRef] [PubMed]

Hendin, Herbert, and Ann Pollinger Haas. 1991. Suicide and guilt as manifestations of PTSD in Vietnam combat veterans. American Journal of Psychiatry 148: 586-91. [PubMed]

Henning, Kris R., and B. Christopher Frueh. 1997. Combat guilt and its relationship to PTSD symptoms. Journal of Clinical Psychology 53: 801-8. [CrossRef]

Hoge, Charles W., and Christopher H. Warner. 2014. Estimating PTSD prevalence in US veterans: Considering combat exposure, PTSD checklist cutpoints, and DSM-5. Journal of Clinical Psychiatry 75: 1439-41. [CrossRef] [PubMed]

Johnson, W. Brad. 2014. The morally-injured veteran: Some ethical considerations. Spirituality in Clinical Practice 1: 16-17. [CrossRef]

Kaiser, Henry F. 1991. Coefficient alpha for a principal component and the Kaiser-Guttman Rule. Psychological Reports 68: 855-58. [CrossRef]

Karairmak, Ozlem, and Berna Guloglu. 2014. Forgiveness and PTSD among veterans: The mediating role of anger and negative affect. Psychiatry Research 219: 536-42. [CrossRef] [PubMed]

Koenig, Harold George, Dana King, and Verna B. Carson. 2012. Handbook of Religion and Health, 2nd ed. New York: Oxford University Press. 
Koenig, Harold G., Nathan A. Boucher, Rev John P. Oliver, Nagy Youssef, Scott R. Mooney, Joseph M. Currier, and Michelle Pearce. 2017. Rationale for spiritually oriented cognitive processing therapy for moral injury in active duty military and veterans with posttraumatic stress disorder. Journal of Nervous and Mental Disease 205: 147-53. [PubMed]

Koenig, Harold G., Donna Ames, Nagy A. Youssef, John P. Oliver, Fred Volk, Ellen J. Teng, Kerry Haynes, Zachary D. Erickson, Irina Arnold, Keisha O'Garo, and Michelle Pearce. 2018a. The Moral Injury Symptom Scale-Military Version. Journal of Religion and Health 57: 249-265. [CrossRef] [PubMed]

Koenig, Harold G., Donna Ames, Nagy A. Youssef, John P. Oliver, Fred Volk, Ellen J. Teng, Kerry Haynes, Zachary D. Erickson, Irina Arnold, Keisha O'Garo, and Michelle Pearce. 2018b. Screening for moral injury: The Moral Injury Symptom Scale - Military Version Short Form. Military Medicine. in press.

Kopacz, Marek S., April L. Connery, Todd M. Bishop, Craig J. Bryan, Kent D. Drescher, Joseph M. Currier, and Wilfred R. Pigeon. 2016. Moral injury: A new challenge for complementary and alternative medicine. Complementary Therapies in Medicine 24: 29-33. [CrossRef] [PubMed]

Lane, Marian E., Laurel L. Hourani, Robert M. Bray, and Jason Williams. 2012. Prevalence of perceived stress and mental health indicators among reserve-component and active-duty military personnel. American Journal of Public Health 102: 1213-20. [CrossRef] [PubMed]

Lee, Deborah A., Peter Scragg, and Stuart Turner. 2001. The role of shame and guilt in traumatic events: A clinical model of shame-based and guilt-based PTSD. Psychology and Psychotherapy: Theory, Research and Practice 74: 451-66. [CrossRef]

Lewis, Helen B. 1971. Shame and guilt in neurosis. Psychoanalytic Review 58: 419-38. [PubMed]

Litz, Brett T., Nathan Stein, Eileen Delaney, Leslie Lebowitz, William P. Nash, Caroline Silva, and Shira Maguen. 2009. Moral injury and moral repair in war veterans: A preliminary model and intervention strategy. Clinical Psychology Reviews 29: 695-706. [CrossRef] [PubMed]

Litz, Brett T., Leslie Lebowitz, Matt J. Gray, and William P. Nash. 2017. Adaptive Disclosure: A New Treatment for Military Trauma, Loss, and Moral Injury. New York: Guilford Publications.

Maguen, Shira, and Kristine Burkman. 2013. Combat-related killing: Expanding evidence-based treatments for PTSD. Cognive and Behavioral Practice 20: 476-79. [CrossRef]

Maguen, S., and Brett Litz. 2012. Moral injury in veterans of war. PTSD Research Quarterly 23: 1-6.

McKinney, Jessica M., Jameson K. Hirsch, and Peter C. Britton. 2017. PTSD symptoms and suicide risk in veterans: Serial indirect effects via depression and anger. Journal of Affective Disorders 214: 100-7. [CrossRef] [PubMed]

Nash, William P., Teresa L. Marino Carper, Mary Alice Mills, Teresa Au, Abigail Goldsmith, and Brett T. Litz. 2013. Psychometric evaluation of the Moral Injury Events Scale. Military Medicine 178: 646-52. [CrossRef] [PubMed]

Pargament, Kenneth I., Bruce W. Smith, Harold G. Koenig, and Lisa Perez. 1998. Patterns of positive and negative religious coping with major life stressors. Journal for the Scientific Study of Religion 37: 710-24. [CrossRef]

Pargament, Kenneth I., Harold G. Koenig, Nalini Tarakeshwar, and June Hahn. 2001. Religious struggle as a predictor of mortality among medically ill elderly patients: A two-year longitudinal study. Archives of Internal Medicine 161: 1881-85. [CrossRef] [PubMed]

Paul, Lisa A., Daniel F. Gros, Martha Strachan, Glenna Worsham, Edna B. Foa, and Ron Acierno. 2014. Prolonged exposure for guilt and shame in a veteran of Operation Iraqi Freedom. American Journal of Psychotherapy 68: 277-86. [PubMed]

Pearce, Michelle, Kerry Haynes, Natalia R. Rivera, and Harold G. Koenig. 2018. Spiritually-integrated cognitive processing therapy: A new treatment for moral injury in the setting of PTSD. Global Advances in Health and Medicine 7: 1-7. [CrossRef] [PubMed]

Pietrzak, Robert H., Risë B. Goldstein, Steven M. Southwick, and Bridget F. Grant. 2011. Prevalence and Axis I comorbidity of full and partial posttraumatic stress disorder in the United States: Results from Wave 2 of the National Epidemiologic Survey on Alcohol and Related Conditions. Journal of Anxiety Disorders 25: 456-65. [CrossRef] [PubMed]

Ramsawh, Holly J., Carol S. Fullerton, Holly B. Herberman Mash, Tsz Hin H. Ng, Ronald C. Kessler, Murray B. Stein, and Robert J. Ursano. 2014. Risk for suicidal behaviors associated with PTSD, depression, and their comorbidity in the US Army. Journal of Affective Disorders 161: 116-22. [CrossRef] [PubMed]

Rosenberg, Morris. 1965. Society and the Adolescent Self-Image. Princeton: Princeton University Press.

Shay, Jonathan. 1994. Achilles in Vietnam: Combat Trauma and the Undoing of Character. New York: Scribner. 
Shay, Jonathan. 2014. Moral injury. Psychoanalytic Psychology 31: 182-91. [CrossRef]

Shrout, Patrick E., and Joseph L. Fleiss. 1979. Intraclass correlations: Uses in assessing rater reliability. Psychological Bulletin 86: 420-28. [CrossRef] [PubMed]

Steenkamp, Maria M., Brett T. Litz, Matt J. Gray, Leslie Lebowitz, William Nash, Lauren Conoscenti, Amy Amidon, and Ariel Lang. 2011. A brief exposure-based intervention for service members with PTSD. Cognitive and Behavioral Practice 18: 98-107. [CrossRef]

Steenkamp, Maria M., Brett T. Litz, Charles W. Hoge, and Charles R. Marmar. 2015. Psychotherapy for military-related PTSD: A review of randomized clinical trials. JAMA 314: 489-500. [CrossRef] [PubMed]

Steger, Michael F., Patricia Frazier, Shigehiro Oishi, and Matthew Kaler. 2006. The Meaning in Life Questionnaire: Assessing the presence of and search for meaning in life. Journal of Counseling Psychology 53: 80-93. [CrossRef]

Steinert, Christiane, Mareike Hofmann, Falk Leichsenring, and Johannes Kruse. 2015. The course of PTSD in naturalistic long-term studies: High variability of outcomes. A systematic review. Nordic Journal of Psychiatry 69: 483-96. [CrossRef] [PubMed]

Thompson, Laura Yamhure, Charles R. Snyder, Lesa Hoffman, Scott T. Michael, Heather N. Rasmussen, Laura S. Billings, Laura Heinze, Jason E. Neufeld, Hal S. Shorey, Jessica C. Roberts, and et al. 2005. Dispositional forgiveness of self, others, and situations. Journal of Personality 73: 313-59. [CrossRef] [PubMed]

Weathers, Frank W., Brett T. Litz, Terence M. Keane, Patrick A. Palmieri, Brian P. Marx, and Paula P. Schnurr. 2013. The PTSD Checklist for DSM-5 (PCL-5) (2013). Scale Available from the National Center for PTSD. Available online: www.ptsd.va.gov (accessed on 14 June 2017).

Witvliet, Charlotte V. O., Karl A. Phipps, M. E. Feldman, and Jean C. Beckham. 2004. Posttraumatic mental and physical health correlates of forgiveness and religious coping in military veterans. Journal of Traumatic Stress 17: 269-73. [CrossRef] [PubMed]

Worthington, Everett L., Jr., and Diane Langberg. 2012. Religious considerations and self-forgiveness in treating complex trauma and moral injury in present and former soldiers. Journal of Psychology and Theology 40: 274-88. [CrossRef]

Yamagishi, Toshio, and Midori Yamagishi. 1994. Trust and commitment in the United States and Japan. Motivation and Emotion 18: 129-66. [CrossRef]

Zigmond, Anthony S., and R. Philip Snaith. 1983. The hospital anxiety and depression scale. Acta Psychiatrica Scandinavica 67: 361-70. [CrossRef] [PubMed] 